\title{
Health systems resilience in fragile and shock-prone settings through the prism of gender equity and justice: implications for research, policy and practice
}

\author{
Wesam Mansour ${ }^{* *}$ (D) Abriti Arjyal ${ }^{2}$, Chad Hughes ${ }^{3}$, Emma Tiange Gbaoh $^{4}$, Fouad Mohamed Fouad ${ }^{5}$, \\ Haja Wurie ${ }^{4}$, Hnin Kalayar Kyaw ${ }^{6}$, Julie Tartaggia ${ }^{3}$, Kate Hawkins ${ }^{7}$, Kyu Kyu Than ${ }^{6}$, Lansana Hassim Kallon ${ }^{4}$, \\ Maya Abou Saad ${ }^{5}$, Obindra Chand ${ }^{2}$, Phone Myint Win ${ }^{6}$, Rouham Yamout ${ }^{5}$, Shophika Regmi ${ }^{2}$, Sushil Baral ${ }^{2}$, \\ Sally Theobald ${ }^{1}$ and Joanna Raven ${ }^{1}$
}

\begin{abstract}
Fragile and shock-prone settings (FASP) present a critical development challenge, eroding efforts to build healthy, sustainable and equitable societies. Power relations and inequities experienced by people because of social markers, e.g., gender, age, education, ethnicity, and race, intersect leading to poverty and associated health challenges. Concurrent to the growing body of literature exploring the impact of these intersecting axes of inequity in FASP settings, there is a need to identify actions promoting gender, equity, and justice (GEJ). Gender norms that emphasise toxic masculinity, patriarchy, societal control over women and lack of justice are unfortunately common throughout the world and are exacerbated in FASP settings. It is critical that health policies in FASP settings consider GEJ and include strategies that promote progressive changes in power relationships. ReBUILD for Resilience (ReBUILD) focuses on health systems resilience in FASP settings and is underpinned by a conceptual framework that is grounded in a broader view of health systems as complex adaptive systems. The framework identifies links between different capacities and enables identification of feedback loops which can drive or inhibit the emergence and implementation of resilient approaches. We applied the framework to four different country case studies (Lebanon, Myanmar, Nepal and Sierra Leone) to illustrate how it can be inclusive of GEJ concerns, to inform future research and support context responsive recommendations to build equitable and inclusive health systems in FASP settings.
\end{abstract}

Keywords: Gender, Equity, Health systems, Resilience, Fragile and shock-prone settings

\section{Introduction}

Fragility, violence, conflict, and other shocks present a critical development challenge, eroding efforts to build healthy, equitable, and inclusive societies. In Fragile and Shock-Prone (FASP) settings, innovative, timely and

*Correspondence: wesamatif@hotmail.com

${ }^{1}$ Department of International Public Health, Liverpool School of Tropical Medicine, Pembroke Place, Liverpool L3 5QA, UK

Full list of author information is available at the end of the article contextually tailored evidence generated in partnership with local and national stakeholders is critical to developing and sustaining equitable and resilient health systems. Power relations experienced by people because of social markers, e.g., gender, disability, education, age, ethnicity and race, can intersect leading to poverty, marginalisation, and associated health challenges, increasing inequities. Intersectionality and its application are gaining traction in global health [1]. It is an approach that supports analysis of how policies can promote gender, original author(s) and the source, provide a link to the Creative Commons licence, and indicate if changes were made. The images or other third party material in this article are included in the article's Creative Commons licence, unless indicated otherwise in a credit line to the material. If material is not included in the article's Creative Commons licence and your intended use is not permitted by statutory regulation or exceeds the permitted use, you will need to obtain permission directly from the copyright holder. To view a copy of this licence, visit http://creativecommons.org/licenses/by/4.0/. The Creative Commons Public Domain Dedication waiver (http://creativecommons.org/publicdomain/zero/1.0/) applies to the data made available in this article, unless otherwise stated in a credit line to the data. 
equity, and justice (GEJ), and strategies to ensure 'no one is left behind' in the attainment of the Sustainable Development Goals [2]. The concept of 'intersectionality' was coined by black American activist, Kimberlé Crenshaw in 1989 as a lens to explain how various forms of inequality can operate together simultaneously, exacerbating each other and intersecting to create different modes of discrimination and privilege [3]. An increased focus on intersectionality has highlighted gaps, for example, in the design of gender-based violence (GBV) programmes. Guidance documents on GBV are often limited in their focus on vulnerable groups, reinforcing the idea of separate and innate identities, rather than overlapping social positions inevitably linked with structures of oppression [4]. There is a growing body of literature that explores the impact of these intersecting axes of inequity in FASP settings, but gaps remain when it comes to what actions can promote GEJ.

Gender norms are social rules that define the behaviour of people of any gender or age in any given society and restrict their gender identity into what is considered to be appropriate [5]. Gender norms that emphasise toxic masculinity and societal control over women occur throughout the world and are exacerbated in FASP settings [6]. Patriarchal control over women limits their role in household decision-making and acts as a precursor for sexual and gender-based violence (SGBV) during conflicts [7]. Lesbian, gay, bisexual, transgender and queer or questioning (LGBTQ+) people are also among the most discriminated, encountering verbal, mental and sexual violence especially during conflicts [8].

The COVID-19 pandemic has further exacerbated gender norms that prescribe caregiving roles, for example, with women being more at risk of infection, both as domestic caregivers and healthcare workers [9]. School closures and travel restrictions limited women's work and economic opportunities since in many contexts, gender norms prescribed that they needed to stay home and take care of their children during the pandemic time as primary domestic caregivers [10]. Refugee girls are only half as likely to enrol in secondary-level education as their male peers, with inequities exacerbated by school closures [11]. In conflicts, many men die, leaving behind female-headed households. During extreme hardship, these households often lack financial resources, which might affect their children who may engage in child labour or early marriage to alleviate the financial burden [12]. These gender norms and power relations play a significant role in determining access to and the outcomes of health services [13]. For example, access to sexual and reproductive health services, including contraception, is often limited, leading to unplanned pregnancies, more children leading to protracted poverty [14]. Elderly people and people with disabilities (PWDs) are often not considered when designing interventions and planning service provision, and FASP settings can exacerbate their vulnerabilities [15], leading to mental health challenges [16]. Discrimination against PWDs can extend to their families, leading to isolation and exclusion from services, aggravated by poor communication systems which restrict access to information and healthcare services.

To improve health outcomes and service delivery to diverse vulnerable populations and marginalised individuals and groups, it is critical that health policies at all levels consider GEJ and include strategies that allow effective implementation and foster progressive changes in power relationships among people of all genders [17]. These can be mechanisms to promote positive gender norms, roles and behaviours [18]. Disease outbreak responses can provide an important catalyst for work on GEJ within preparedness and response efforts-improving the effectiveness of health interventions and promoting GEJ [17].

ReBUILD for Resilience (ReBUILD) is a multi-country health systems research consortium (https://www.rebui ldconsortium.com/). Our work focuses on resilience in Lebanon, Myanmar, Nepal and Sierra Leone and is underpinned by a conceptual framework that is grounded in a broader view of health systems as complex adaptive systems (Fig. 1) [19]. Our outcomes have gender and equity at their heart (as illustrated by the red rectangles).

Each ReBUILD country has faced shocks that impacted its health system, and each continues to face challenges brought by COVID-19. The ReBUILD GEJ Working Group held a set of webinars to initiate a dialogue across the consortium and beyond to explore our conceptualisation of GEJ in FASP settings. Different organisations and international consultants with expertise in GEJ participated in these discussions and provided empirical examples to promote GEJ in health system research. For the purposes of this paper, we gathered contextual evidence and tacit knowledge within our evolving settings to understand how the GEJ concepts link to our resilience framework. To inform our analysis and to structure this paper, we clustered the resilience framework nodes around three cross-cutting areas: governance, decisionmaking and accountability; human resources for health; and learning, monitoring and evaluation. For each area, we mapped the implications for GEJ research, policy and practice, including illustrative examples from ReBUILD. Our learning is synthesised here with priority research areas and ways forward for each of the three cross cutting areas highlighted to inform our ReBUILD work and also support policymakers, governmental officials at all levels, academics and health system researchers in FASP 


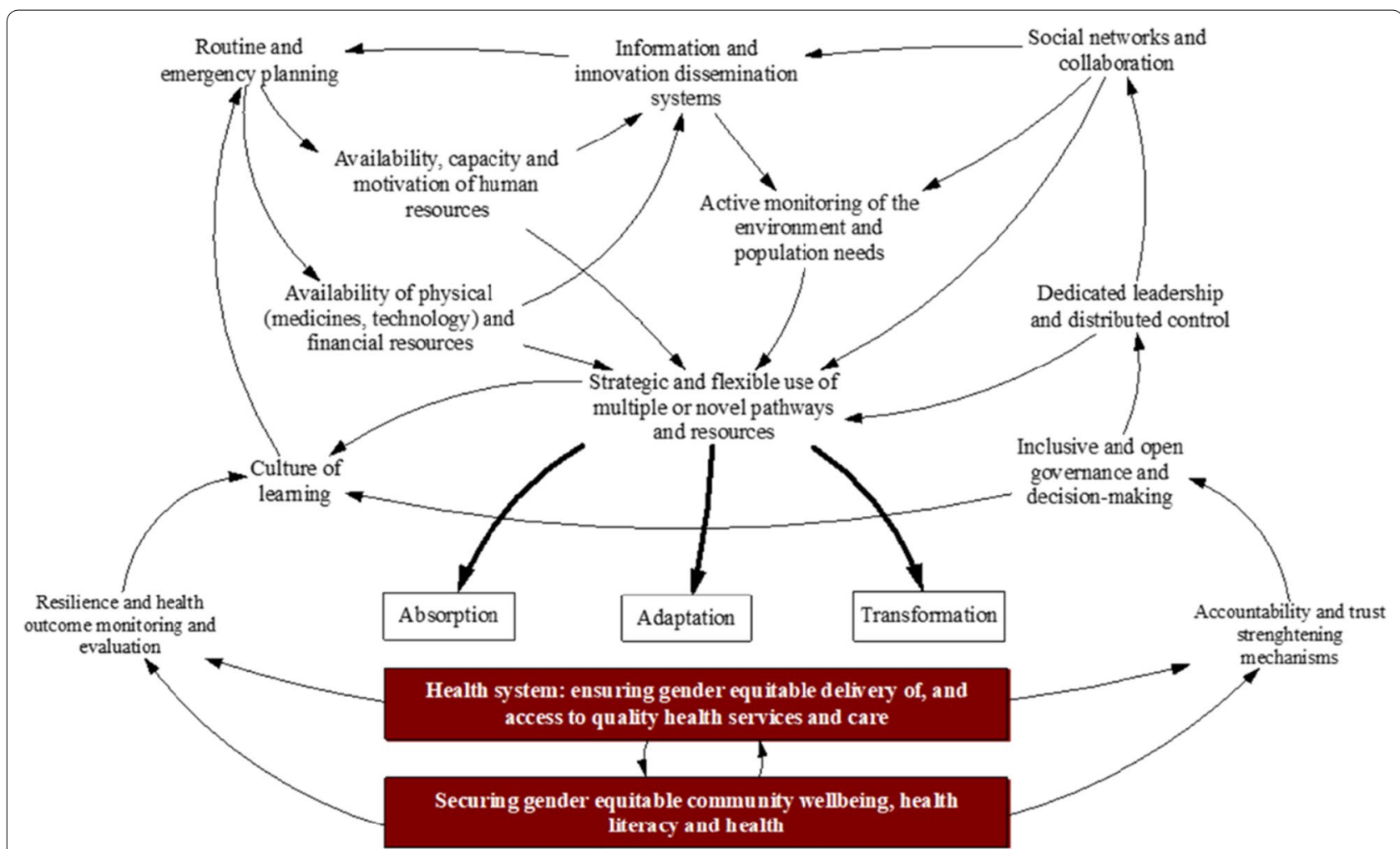

Fig. 1 ReBUILD for resilience framework 19

settings and beyond to support building equitable and inclusive health systems within these fragile settings.

\section{Inclusion, open governance, decision-making and accountability}

The politics of intervention implementation, the diverse actors involved, and contextually specific power structures can influence service provision at various levels of health systems in FASP settings. Improving accountability and decision-making processes for engaging communities in health service planning is important.

Nepal has a new federal structure of the health system functioning at three tiers-federal, provincial, and local levels. With federalism came a considerable shift in Nepal's governance mechanism, which is now more inclusive with decentralised decision-making. Local governance structures mandated the representation of marginalised groups including women and disadvantaged/ minorities in various positions/committees. These representatives are responsible for executive and judicial functions and with this comes greater power. However, there is little meaningful participation from marginalised groups, with men taking most decision-making roles. Multiple GEJ responsive strategies were developed in the health sector [20,21], partially driven by the
2015 earthquake and other environmental and economic shocks that highlighted the neglect of marginalised groups [21]. However, mainstreaming strategies into the institutional and implementation frameworks and ensuring government capacity to deliver them is a challenge.

Since Myanmar's independence in 1948, armed conflicts between Myanmar military and Ethnic Armed Organizations (EAOs) have contributed to a fractured health system. Prior to the military deposing the existing government and assuming power in February 2021, Myanmar supported parallel health systems: government-run services in government-controlled areas under the National Health Plan (NHP), and those run by Ethnic Health Organisations (EHOs) serving ethnic minorities in conflict-affected areas. Women's participation in decision-making in public and political life, including peace processes, has received growing attention in recent years. Following the 2015 election, where Aung San Suu Kyi became de facto leader of the country, the percentage of women in Myanmar's Hluttaw (council of ministers) more than doubled to $10.5 \%$, but is still below the Asian average (19.4\%) and global average (23.3\%) [22]. Since the 2021 military coup, most services in all areas of the country are disrupted [23]. During the 2010 shift to a military-civilian government, the NHP outlined a path 
towards decentralisation with minimal involvement of EHOs, but progress was slow, perhaps due to the overall weakness of the health system including inadequate managerial capacity [24]. Integrating goals and actions to address GEJ issues into the NHP and indicators that allow for more robust gender and intersectional analysis, will build accountability for GEJ-considerate decisionmaking at all health system levels [24]. Another priority step is to build on existing GEJ supportive mechanisms/ approaches, including formalising permanent seats in health decision-making bodies at all levels for civil-society organisations representing women and marginalised groups, which is currently an ad-hoc informal approach.

In Lebanon, health governance often works in favour of the political elite, representatives of sectarian political powers and powerful lobbies (private hospitals, physicians, pharmaceutical companies) rather than in the engagement of health policies in providing health for all [25]. This results in inappropriate, poorly reinforced, inapplicable decisions, and greater injustice in access of vulnerable populations to affordable and quality healthcare. Key priorities include restructuring the decision-making process, and implementing new ways of evidence-based, decentralised, equitable and population-centred healthcare governance that is informed by research. Channelling aid to Syrian refugees through public institutions also faces challenges of lack of transparency, sectarianism and clientelism [26]. The international response is complex and some of this is disconnected from the local context, with limited transparency in financial transactions [26], leading to untrusted and inequitable services. Accountability and transparency in auditing, financial reporting and budgeting are needed across all health actors [26].

\section{Actions and way forward}

The ReBUILD learning and discussions initiated across our consortium and beyond, focused on approaches that could promote inclusion, open governance, decisionmaking and accountability for GEJ in health systems, and the potential opportunities presented by decentralisation (as highlighted by the Nepalese context) Moving forward in ReBUILD we will work collaboratively in a"Learning sites" approach which will provide an opportunity to explore decision-making and governance at the local level [27]-working with local stakeholders to map what is happening and identifying required actions, e.g., making decision-making more gender equitable and inclusive, ensuring marginalised groups are heard, and strengthening accountability mechanisms. These actions can be implemented, documenting the innovations, reflections and adaptations over time, taking note of what changes and why, what is blocked, and what facilitates action, innovation, and equitable processes.

Community engagement, with the meaningful participation of different groups in planning decision-making and execution is important. For example, in ReBUILD we will move this forward by evaluating community feedback mechanisms for greater accountability, improved quality, increased trust in the health system, and working with community health workers (CHWs) to support their engagement in decision-making at the community level. Health systems that have open and inclusive governance structures, where local leadership and distributed control of resources are emphasised, are likely to be more efficient in implementing, testing and revising adaptive solutions for service delivery in times of shock. We will also explore how gender and leadership can be strengthened at the local level.

\section{Responsive human resources for health policies for gender, equity and justice}

In FASP settings, there is an urgent need to understand how human resources (HR) management can contribute to health systems rebuilding. However, rebuilding with competent and equitably distributed workforce is often complex [28]. In Lebanon, HR challenges are exacerbated by the severe economic crisis since 2019 , followed by COVID-19, leading to a dramatic decline in health workers' income, especially among already underpaid nonphysician workers [29]. Health facilities which have not received payment from public insurance schemes [30] resorted to cutting salaries and dismissing personnel [31], leading to an exodus of physicians [32]. This situation negatively impacts on the quality [33], appropriateness [34] and availability [35] of healthcare services and jeopardises the COVID-19 response, depriving the most vulnerable of testing and treatment. A lack of female healthcare providers was a challenge faced by female Syrian refugees [36]. This may become more of a problem as $80 \%$ of nurses are women [37] and are facing greater lay-offs and wage reductions than their male counterparts [38]. The informal health sector emerged as a shortterm solution to these gaps [39], but workers need to be integrated into the national health system, with payment, regulation, training and support provided.

HR challenges are a perennial problem for Nepal's health system [40], and have continued with the introduction of the new federal structure. The chronic shortage of staff, problems deploying health workers to rural areas, and limited benefits and motivation led to absenteeism which influenced service provision and imposed further challenges to HR management during COVID19 [41]. With an expanding urban poor and changing health needs, the health workforce lacks the capacity to 
address populations' needs. Although $40 \%$ of the health workforce in Nepal are women, most are not in leadership positions [42]. These issues can be addressed by supporting HR at all levels through strengthening capacity, enabling women leaders, and creating reward systems to motivate health workers to provide services in hard-toreach areas.

In Myanmar, the 2021 military coup risks reversing recent gains in supporting a gender equitable health workforce. Medical personnel were among the first to join the civil disobedience movement and have since been under threat of arrest. This frontline role taken by healthcare workers, and concerns for their safety, limits their capacity to provide healthcare, including free services to the public outside formal structures. This led to a severe shortage of health staff and serious challenges in maintaining basic health services, compounded by COVID-19.. Before the coup, university entry and opportunities for female students were equal to males, and educational reform was a national priority, supporting health workforce education and training. However, career pathway into policy making roles is less equitable: men and women doctors appear to have equal opportunities, but nurses, where the majority are women, have fewer opportunities. Since the coup, most universities have closed, and reform plans have halted [43]. Once the country stabilises and educational reform is again on the agenda, a culture of learning in relation to GEJ issues for medical, public and allied health students could be nurtured by embedding critical thinking, decision-making and problem-solving skills into education.

In Sierra Leone, the health system is characterised by inequitable and inefficient allocation of HR [44], which is further exacerbated by shocks. During the Ebola outbreak, frontline health workers were mostly from lower cadres and women (out of 11,325 deaths, $59-75 \%$ were women, including health workers) [45]. In the initial phase of the Ebola response, there were insufficient infection prevention and control materials [46], which increased the infection rate, putting women at risk. CHWs took on critical roles during the Ebola response and in the COVID-19 response including education about safety, contact tracing and visiting those quarantined. Societal and gender norms continue to play out, with female CHWs facing challenges travelling around the community due to the nature of the terrain and mode of transportation available, female supervisors not being recognised by male supervisees, the dual burden of community and household work, including home schooling during lockdown. This limits their ability to engage in other income generating activities, creating challenges for female-headed households. Infection mitigation measures such as curfews and lockdowns (including inter-district lockdowns) created significant threats to female-run micro-level businesses e.g., street hawking including food vendors, market traders, retailing and domestic services, drastically impacting on women's livelihoods and economic security with wider implications for food security. CHWs' workloads during COVID-19 prevented them from engaging in other income generation exercises, further decreasing their earning power, and government incentives were irregular [47].

\section{Actions and way forward}

We identified several ways that HR policy and practice could be improved, so that health systems in FASP contexts can better support health workers in their critical roles and enable them to be more responsive to GEJ concerns. Including people of all genders and backgrounds in the health workforce would help develop GEJ responsive and transformative HR. Policy examples include recruitment and retention, training and career development policies that promote equal opportunities and counter discrimination. These policies need to be disseminated and operationalised by sub-national level managers who can adapt these polices so that they respond to the local contexts. Accurate information about the numbers and distribution of staff in rural and urban areas can inform decision-making so that there is equitable deployment of staff, reflecting specific contextual needs. For example, in ReBUILD, we will promote the availability and use of gender and equity disaggregated data on HR in learning sites to inform actions and develop evidence on CHWs' gendered experiences and needs related to providing services in the context of fragility, COVID-19, and future shocks.

\section{A culture of learning, monitoring and evaluation for gender, equity, and justice}

In learning health systems, evidence and data is used routinely to inform day-to-day decision-making and to respond to shocks. In our settings, there is a need for strong accountability mechanisms, informing how routine data systems can capture equity concerns and inform decision-making. Monitoring and evaluation of resilience depend on appropriate metrics and processes that are used to appraise health system resilience, including measures of preparedness, responsiveness and recovery, and how these are operationalised in FASP settings.

Sierra Leone's health system has dealt with multiple shocks, e.g., civil war, Ebola and COVID-19. The epidemics led to the establishment of the Emergency Operation Centre to lead the responses. Despite the government's effort to increase women representation in leadership and decision-making spaces by $30 \%$, currently leadership and decision-making roles are male dominated, 
and GEJ considerations are often overlooked. This was evident in the recent Ebola outbreak response which failed to adequately plan for vulnerable groups, leading to decreases in service use and worsening outcomes for pregnant women, lactating mothers, under-fives and PWDs due to the fear of infection $[44,48]$. The response also overlooked women and girls' caregiving roles, and the added risk they face during outbreaks [48, 49]. Many of the Ebola burial teams were made up of young men, and because of limited psychosocial support, their mental wellbeing was affected [50], which can have long-term implications. The post-Ebola recovery plan considered gender and social protection [48], but this has not shaped ongoing practice or a culture of change and the subsequent national health security plan (2018-2020) appears to lack GEJ considerations. The translation of gender transformative policies was influenced by gender and societal norms, resulting in unintended consequences. For example, the CHW policy developed after the Ebola was design to recruit more female CHWs but in practice more male CHWs were recruited. National measures are being put in place to address these norms, including some policies and laws to promote GEJ. However, a more consultative approach should be considered to ensure intended implementation, ensuring stakeholders and social structures are engaged to gradually engender change.

In Nepal, limited indicators in the Health Management Information System (HMIS) restrict robust gender and intersectionality analysis and impede the planning of inclusive health services. There is a need to strengthen the HMIS to incorporate wider social stratifiers, disaggregated analysis and data use in local decision-making, with stakeholder capacity development at different levels.

\section{Actions and way forward}

Our discussions highlight how investments in monitoring and evaluation are limited compared to other health systems areas, in addition to poor use of routine data for equity analysis and driving change. There is need to invest in developing health indicators to assess equity from an intersectional standpoint (e.g., by gender, age, dis/ability), and to use this disaggregated data to assess equity in ways that are usable, acceptable, relevant and actionable at different levels, including within community health. This and other relevant data (including from qualitative and participatory research processes) should inform and strengthen a culture of embedded and responsive M\& E within annual health systems review processes and building decision-making space to actively address local level inequities. This requires training and building networks for change to inspire action. We noted the opportunity that learning sites present local health systems actors to identify areas for improvement, innovate for action and learn from the process, thus embedding a culture of reflection and learning into the system. Dissemination of GEJ information (i.e., policy briefs and case studies) that can be used by policymakers and implementers is important. Identifying and investing in innovative and culturally appropriate techniques (e.g., using local languages and different delivery mediums) to communicate messages to marginalised group will be key. There is a need to strengthen the political will and demand for monitoring, evaluation and learning systems that promote equity and inclusiveness. This may include nurturing change champions and trusted institutions to promote GEJ within health systems, while building accountability and responsiveness.

\section{Conclusion}

The ReBUILD for Resilience framework identifies links between different capacities and enables identification of feedback loops which can drive or inhibit the emergence and implementation of resilient approaches. The framework acknowledges that resilience is not an end in itself, but a step towards securing equitable community wellbeing, health literacy and health. We applied it to four different case studies to illustrate how it can be inclusive of GEJ concerns, to inform future research and support contextually sensitive recommendations to build equitable and inclusive health systems in FASP settings. Moving forward a learning sites approach will help explore decision-making and governance at the local level and promote the availability and use of gender and equity disaggregated data on HR to inform actions and develop the evidence base on health workers' gendered experiences and needs in FASP settings.

\footnotetext{
Abbreviations

CHWs: Community health workers; EAOs: Ethnic Armed Organizations; EHOs: Ethnic Health Organizations; FASP: Fragile and shock-prone; GEJ: Gender, equity and justice; HMIS: Health Management Information System; HR: Human resources; PWDs: People with disabilities; SGBV: Sexual and gender-based violence.
}

\section{Acknowledgements}

The Gender, Equity and Justice Working Group of ReBUILD for Resilience and the authors of this paper are very grateful to Professor Sophie Witter, Professor of International Health Financing and Health Systems in Queen Margaret University, for her valuable time and useful comments as a peer reviewer, which helped us to improve the paper.

\section{Authors' contributions}

WM conceptualised and designed the analysis, supported the analysis and interpretation in each country, synthesised the themes, and drafted the manuscript. (HW, ETG and LHK), (AA, SB, OC, and SR), (CH, HKK, JT, KKT, and PMW), and (MF, RY, and MAS) contributed to the design of the paper, reviewed, analysed, and interpreted documents, in Sierra Leone, Nepal, Myanmar and Lebanon respectively. JR, ST, and KH contributed to the conceptualisation and design of the paper, and critically reviewed drafts of the manuscript. JR provided oversight of the whole writing process. All authors agreed to be 
accountable for all aspects of the work. SW (not an author) peer-reviewed it and helped us improve the paper. All authors read and approved the final manuscript.

\section{Funding}

This work was funded by the Foreign, Commonwealth and Development Office (FCDO), UK Aid, under the ReBUILD for Resilience Research Programme Consortium (PO 8610).

\section{Availability of data and materials}

Not applicable.

\section{Declarations}

\section{Ethics approval and consent to participate}

Ethical approval was not required for this debate as it did not involve any human participants or animal subjects.

\section{Consent for publication}

Not applicable.

\section{Competing interests}

The authors declare that they have no competing priorities, and that the funders take no responsibility for the views expressed in this article.

\section{Author details}

${ }^{1}$ Department of International Public Health, Liverpool School of Tropical Medicine, Pembroke Place, Liverpool L3 5QA, UK. ${ }^{2}$ HERD International, Kathmandu, Nepal. ${ }^{3}$ Burnet Institute, Melbourne, Australia. ${ }^{4}$ College of Medicine and Allied Health Sciences, University of Sierra Leone, Freetown, Sierra Leone. ${ }^{5}$ Faculty of Health and Sciences, American University in Beirut, Beirut, Lebanon. ${ }^{6}$ Burnet Institute, Yangon, Myanmar. ${ }^{7}$ Pamoja Communications Ltd., Brighton, UK.

Received: 29 October 2021 Accepted: 8 February 2022

Published online: 21 February 2022

\section{References}

1. Cooper J, Khanna R, Smyth I, et al. Introduction: gender, development, and health. Gend Dev. 2021;29(1):1-10. https://doi.org/10.1080/13552 074.2021.1885221.

2. World Health Organization. Incorporating intersectional gender analysis into research on infectious diseases of poverty: a toolkit for health researchers. 2020. ISBN 978-92-4-000845-8 (electronic version). https:// creativecommons.org/licenses/by-nc-sa/3.0/igo). Accessed 23 June 2021.

3. Crenshaw K. Demarginalizing the intersection of race and sex: a black feminist critique of antidiscrimination doctrine, feminist theory and antiracist politics, vol. 1989, no 1, Article 8, University of Chicago Legal Forum. Accessed 18 Dec 2021. http://chicagounbound.uchicago.edu/uclf/vol19 89/iss 1/8.

4. Michelis I. "Picked up, misused, abused, changed": intersectionality in the humanitarian discourse on gender-based violence. RESEARCH BRIEF. University of Cambridge, 2020. Accessed 18 Dec 2021. https://www.acade mia.edu/43022869/_Picked_up_misused_abused_changed_Intersecti onality_in_the_Human.itarian_Discourse_on_Gender_Based_Violence

5. Save the Children. Gender roles can create lifelong cycle of inequality. 2021. Accessed 18 Dec 2021. https://www.savethechildren.org/us/chari ty-stories/how-gender-norms-impact-boys-and-girls

6. Stewart F. Root causes of violent conflict in developing countries. Br Med J. 2002;324(7333):342-5. https://doi.org/10.1136/bmj.324.7333.342.

7. Ekhator-Mobayode U. Does armed conflict increase a woman's risk of suffering intimate partner violence? 2020. https://aus.libguides.com/apa/ apa-blog. Accessed 7 Apr 2021.

8. Barbelet V. Male gender-based violence: a silent crisis. Overseas Development Institute. 2014. https://odi.org/en/insights/male-gender-basedviolence-a-silent-crisis/. Accessed 16 Apr 2021.

9. Villareal A. Coronavirus pandemic exacerbates inequalities for women, UN warns world news the guardian, 2020. https://www.theguardian. com/world/2020/apr/11/un-coronavirus-pandemic-gender-inequalitieswomen. Accessed 16 Apr 2021.

10. Muraya K. Gender and COVID-19 in Africa. The Gender and COVID-19 Working Group. 2020. https://www.genderandcovid-19.org/wp-content/ uploads/2020/10/Gender-and-COVID19-in-Africa.pdf. Accessed 23 June 2021.

11. Plan International. COVID-19 school closures around the world will hit girls the hardest. 2020. https://plan-international.org/blog/2020/03/ covid-19-schoolclosures-hit-girls-hardest. Accessed 6 Mar 2021.

12. The State of Food Insecurity in the World. Countries in protracted crisis: what are they and why do they deserve special attention? Common features of countries in protracted crisis. 2020. http://www.fao.org/3/i1683e/ i1683e03.pdf. Accessed 8 Feb 2021.

13. Morgan R, George A, Ssali S, et al. How to do (or not to do) gender analysis in health systems research. Health Policy Plan. 2016;31(8):1069-78. https://doi.org/10.1093/heapol/czw037.

14. The United Nations Children's Fund (UNICEF). Resilience, humanitarian assistance and social protection for children in Europe and Central Asia (Social Protection Regional Issue Brief: 2). August 2017. https://www. unicef.org/eca/media/2671/file/Social_Protection2.pdf. Accessed 2 Apr 2021.

15. de Leeuw L. The situation of older refugees and refugees with disabilities, injuries, and chronic diseases in the Syria crisis. EEN: field exchange 48. November 2014. www.ennonline.net/fex/48/thesituation. Accessed 23 June 2021.

16. Al Laham D, Ali E, Mousally K. Perceptions and health-seeking behaviour for mental illness among Syrian refugees and Lebanese community members in Wadi Khaled, North Lebanon: a qualitative study. Community Ment Health J. 2020;56(5):875-84. https://doi.org/10.1007/ s10597-020-00551-5.

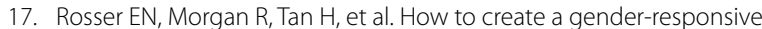
pandemic plan: addressing the secondary effects of COVID-19. Gender and COVID-19 project 2021.

18. Theobald S, Morgan R, Hawkins K, et al. The importance of gender analysis in research for health systems strengthening. Health Policy Plan. 2017;32:v1-3. https://doi.org/10.1093/heapol/czx163.

19. Diaconu K, Witter S. Understanding the resilience of health systems. Chapter 6. In:Bozogmehr et al. editor. Health policy and systems responses to forced migration; 2020. Springer. https://doi.org/10.1007/ 978-3-030-33812-1.

20. Ministry of Health and Population of Nepal. Health sector gender equality and social inclusion strategy. 2009.

21. Ministry of Health and Population (MOHP). Gender equality and social inclusion strategy of the health sector; 2018. https://mohp.gov.np/downl oads/Gender\%20Equality\%20and\%20Social\%20Inclusion\%20Strategy\% 20English\%20Version\%20FINAL.pdf. Accessed 15 Mar 2021.

22. Enlightened Myanmar Research Foundation (EMReF). Gender and political participation in Myanmar. October 2020. Accessed 10 Jan 2022. https://www.emref.org/sites/emref.org/files/publication-docs/gender_ and_political_in_myanmarenglish_online.pdf.

23. Latt NN, Cho SM, Htun NMM, et al. Healthcare in Myanmar. Nagoya J Med Sci. 2016;78(2):123-34.

24. World Health Organization. The Republic of the Union of Myanmar health system review. Manila: WHO Regional Office for the Western Pacific; 2014.

25. Mansour $\mathrm{H}$. The Health Sector in Lebanon: there is no alternative to radical solutions. Al Akhbar Newspaper; 2019. https://al-akhbar.com/Opini on/272511. Accessed 16 Apr 2021

26. Grunewald F, Brangeon S, Karroum N. Collective resolution to enhance accountability and transparency in emergencies: Lebanon report; 2017. Transparency International: Berlin. https://images.transparencycdn.org/ images/2017_CREATE_Lebanon_EN.pdf. Accessed 5 Mar 2021.

27. Sheikh K, Abimbola S, editors. Learning health systems: pathways to progress. Flagship report of the Alliance for Health Policy and Systems Research. Geneva: World Health Organization; 2021. Licence: CC BY-NCSA 3.0 IGO.

28. Roome E, Raven J, Martineau T. Human resource management in postconflict health systems: review of research and knowledge gaps. Confl Health. 2014. https://doi.org/10.1186/1752-1505-8-18.

29. El-Jardali F, Dimassi H, Dumit N, et al. A national cross-sectional study on nurses' intent to leave and job satisfaction in Lebanon: implications 
for policy and practice. BMC Nurs. 2009. https://doi.org/10.1186/ 1472-6955-8-3.

30. Human Rights Watch, Lebanon: Health Workers'Safety Neglected during Covid-19. 2020. https://www.hrw.org/news/2020/12/10/lebanon-healthworkers-safety-neglected-during-covid-19. Accessed 20 Mar 2021.

31. Hamieh R. It fell like a "thunderbolt above our heads." $35 \%$ of nurses are without work or for half their salary! El Marada. 2020. https://elmarada. org/679723. Accessed 10 Feb 2021.

32. Nakhoul S, Abdallah I. Hundreds of disillusioned doctors leave Lebanon, in blow to healthcare. https://www.reuters.com/article/us-lebanon-crisishealthcare-insight-idUSKBN27S14W. Accessed 25 Feb 2021.

33. Al Ghousain I. 16 Thousand worker in the nursing sector are without protection. IM Lebanon; 2020. https://www.imlebanon.org/2020/03/24/ nurses/. Aaccessed 23 June 2021.

34. The National Commission for Lebanese Women, The United Nations Entity for Gender Equality and Women's Empowerment, The United Nations Population Fund, \& the World Health Organization 2020. Gender alert on Covid-19 Lebanon in focus: women, gender equality and health [Issue No.4]. https://lebanon.unfpa.org/en/publications/gender-alertcovid-19-lebanon-issue-no-4-focus-women-gender-equality-and-health. Accessed 12 May 2021.

35. Diet R. Hospitals steal patients: «social security differences» are equal to the hospital bill. Al Akhbar Newspaper 2020. https://al-akhbar.com/ Community/297717. Accessed 22 Mar 2021.

36. Kabakian-Khasholian T, Mourtada R, Bashour H, et al. Perspectives of displaced Syrian women and service providers on fertility behaviour and available services in West Bekaa, Lebanon. Reprod Health Matters. 2017;25(sup1):75-86. https://doi.org/10.1080/09688080.2017.1378532.

37. The National Commission for Lebanese Women, The United Nations Entity for Gender Equality and Women's Empowerment, The United Nations Population Fund, \& the World Health Organization. (2020). Gender alert on Covid-19 Lebanon in focus: women, gender equality and health [Issue No.4]. https://lebanon.unfpa.org/en/publications/genderalert-covid-19-lebanon-issue-no-4-focus-women-gender-equality-andhealth. Accessed 13 Apr 2021.

38. The National Commission for Lebanese Women, The United Nations Entity for Gender Equality and Women's Empowerment, The United Nations Population Fund, \& the World Health Organization. (2020). Gender alert on Covid-19 Lebanon in focus: women, gender equality and health [Issue No.2]. https://lebanon.unfpa.org/sites/default/files/pub-pdf/ gender\%20alert\%20on\%20covidlebanon\%20issue\%202\%20english.pdf. Accessed 16 May 2021

39. Archer D. (Rep.). International Institute for Environment and Development. 2018. http://www.jstor.org/stable/resrep16709. Accessed 8 Feb 2021.

40. European Union and The Britain Nepal Medical Trust. 2016. HRH in Nepal—analysis of policy and practices Situational Analysis of Human Resource for Health in Public and Private Sectors in Nepal HRH in Nepal_-Situational Analysis. http://www.britainnepalmedicaltrust.org.uk/ wp-content/uploads/2016/01/Situation-Analysis-of-Human-ResourceFor-Health.pdf. Accessed 5 May 2021.

41. Sherchand J. Human resources for health $(\mathrm{HRH})$ and challenges in Nepal. J Inst Med. 2013;35(1):1-2.

42. Ministry of Health and Population and Nepal health sector support program. 2013. Human Resource of health Nepal Country Profile. http:// www.nhssp.org.np/NHSSP_Archives/human_resources/HRH_Nepal_profi le_august2013.pdf. Accessed 3 July 2021.

43. Soe MZ, Swe AM, Aye NKM, Mon NH. Reform of the education system: case study of Myanmar. 2017. https://www.pic.org.kh/images/2017Resear ch/20170523\%20Education_Reform_Myanmar_Eng.pdf. Accessed 28 June 2021.

44. Govindaraj R, Herbst C, Clark J. Strengthening post-Ebola health systems: from response to resilience in Guienea, Liberia, and Sierra Leone. Washington, D.C: World Bank Group; 2018. https://openknowledge.worldbank. org/handle/10986/27618. Accessed 23 June 2021.

45. Relief Web-Sierra Leone. The impact of COVID-19 Pandemic on women: lessons from the Ebola outbreak in W/Africa. 2020. https://reliefweb.int/ report/sierra-leone/impact-covid-19-pandemic-women-lessons-ebolaoutbreak-wafrica. Accessed 23 June 2021.

46. Barrera-Cancedda AE, Riman KA, Shinnick JE, et al. Implementation strategies for infection prevention and control promotion for nurses in
Sub-Saharan Africa: a systematic review. Implementation Sci. 2019;14:111. https://doi.org/10.1186/s13012-019-0958-3.

47. ReBUILD for Resilience. The gendered experience of close-to-community providers in fragile and shock-prone (FASP) settings: implications for policy and practice during and post COVID-19. 2021. https://www.rebui Idconsortium.com/projects/responsive-fund-round-one-covid-19/. Accessed 14 July 2021.

48. Government of Sierra Leone 2015. National Ebola Recovery Strategy for Sierra Leone: 2015-2017. Freetown: Government of Sierra Leone. (https:// reliefweb.int/sites/reliefweb.int/files/resources/sierra_leone_ebola_strat egy_030715.pdf). Accessed 23 June 2021.

49. Hay K, McDougal L, Percival V, et al. Disrupting gender norms in health systems: making the case for change. The Lancet. 2019;393(10190):253549. https://doi.org/10.1016/50140-6736(19)30648-8.

50. Garoff F. Psychosocial support during the Ebola outbreak in Kailahun Sierra Leone. Intervention. 2015;13(1):76-81. https://doi.org/10.1097/WTF. 00000000000000772015 .

\section{Publisher's Note}

Springer Nature remains neutral with regard to jurisdictional claims in published maps and institutional affiliations.

Ready to submit your research? Choose BMC and benefit from:

- fast, convenient online submission

- thorough peer review by experienced researchers in your field

- rapid publication on acceptance

- support for research data, including large and complex data types

- gold Open Access which fosters wider collaboration and increased citations

- maximum visibility for your research: over $100 \mathrm{M}$ website views per year

At BMC, research is always in progress.

Learn more biomedcentral.com/submissions 